\title{
CLIFF-NESTING BARN SWALLOWS
}

DAVID RAITT, Box 401, The Pas, MB, R9A 1K5, E-mail: <grayjay1@mts.net>

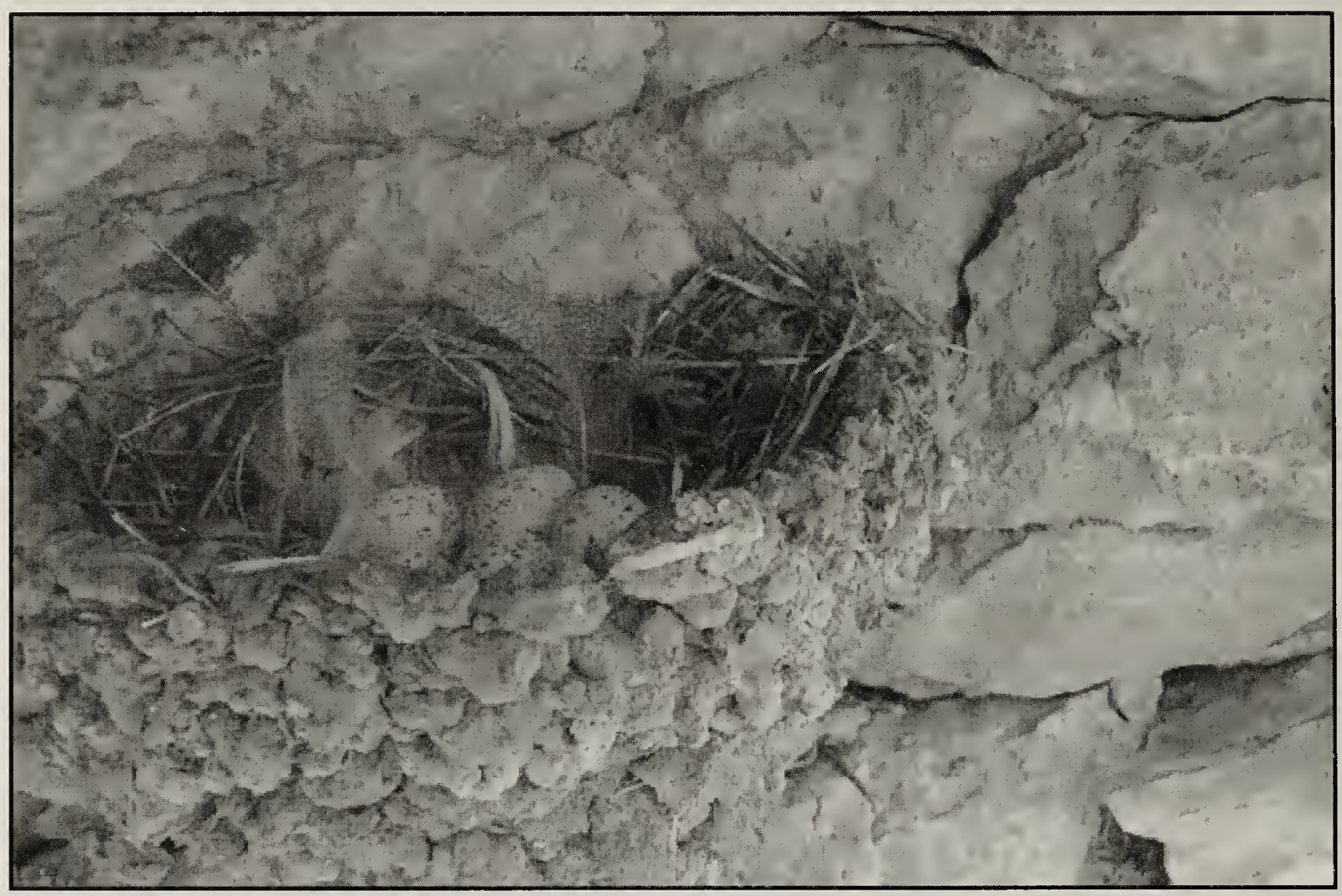

Figure 4. Nest 1 with 5 eggs on June 9, 2007.

D. Raitt

Of Barn Swallow nesting, The Birds of North America states: "originally nesting primarily in caves, the Barn Swallow has almost completely converted to breeding under the eaves of or inside, artificial structures such as buildings and bridges. In North America, this shift in nest sites began before European settlement and was virtually completed by the mid-twentieth century; nowadays natural nestings are rarely seen and usually reported in print if they occur." Speich et al. reported "a review of barn swallow nestings in natural sites reveals that few reported natural nest sites are presently active in North America." A natural nesting occurrence in Wisconsin consisted of three Barn Swallow nests "about eight feet above the water and...well protected from above by the overhanging sandstone cliff." Richard Knapton reported Barn Swallows nesting on Mason Island in Dawson Bay, Lake Winnipegosis in Manitoba where "three of the nests were built in natural cavities of the rock, and three were built on the cliff face itself." ${ }^{3}$

I observed Barn Swallows nesting on the rock face of an island in Bradley Lake, Manitoba (about $40 \mathrm{~km}$ southeast of The Pas), in the summer of 2007. The island is largely rectangular (approximately 130 meters by 40 meters) and is angled from southwest to northeast. The nests were on the southeast, east, and north faces of the island.

\section{Field Observations, 2007}

On March 24, I snowshoed in to the site and found 18 mud nests that I believed were made by Barn Swallows, and one stick nest of unknown origin. The mud nests varied from half cups 


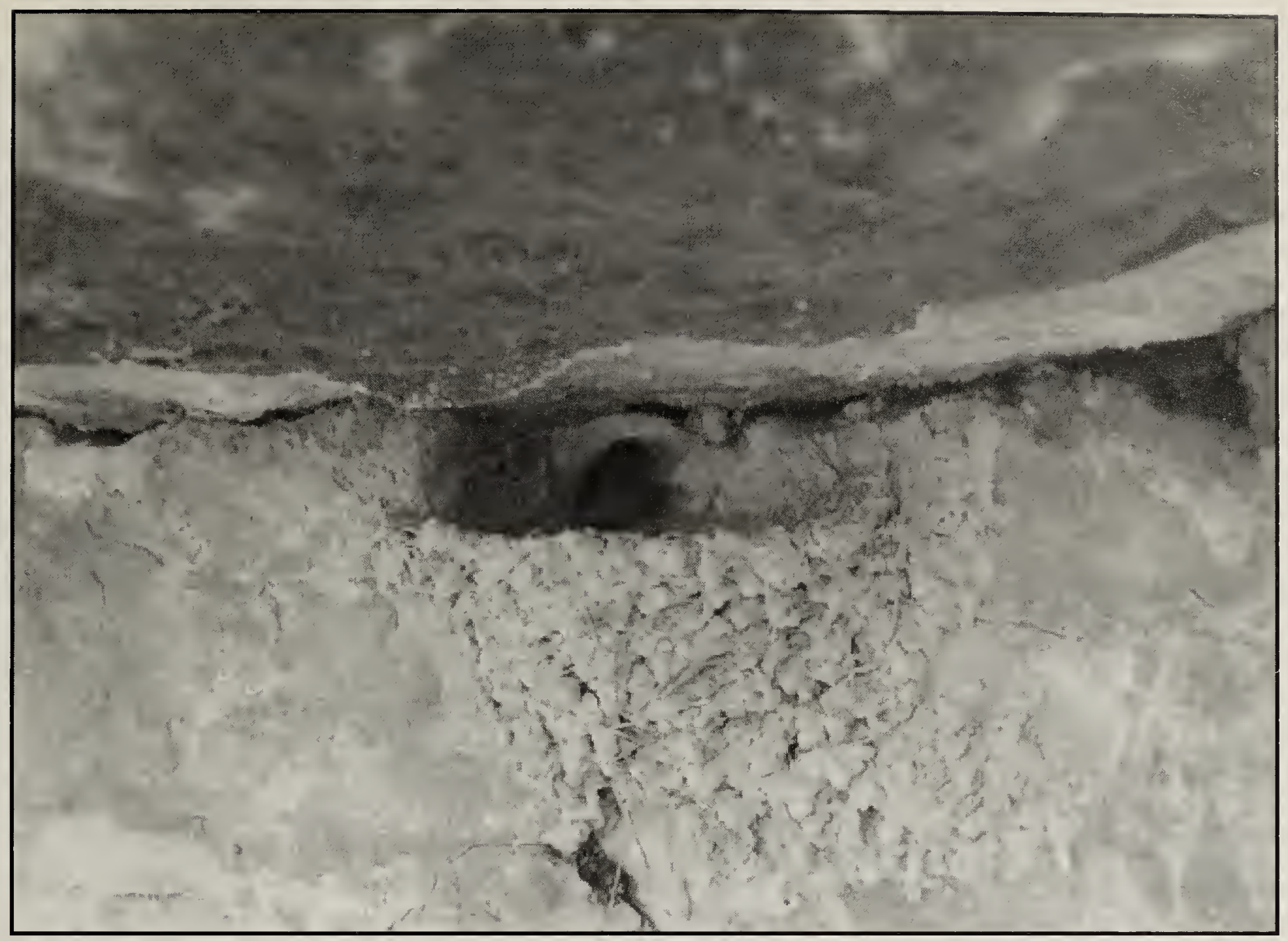

Figure 2. Nest 4, attached to a vertical surface protected by a rock overhang. This nest, photographed on July 13, was built after an earlier nest at this location had fallen from the cliff.

D. Raitt

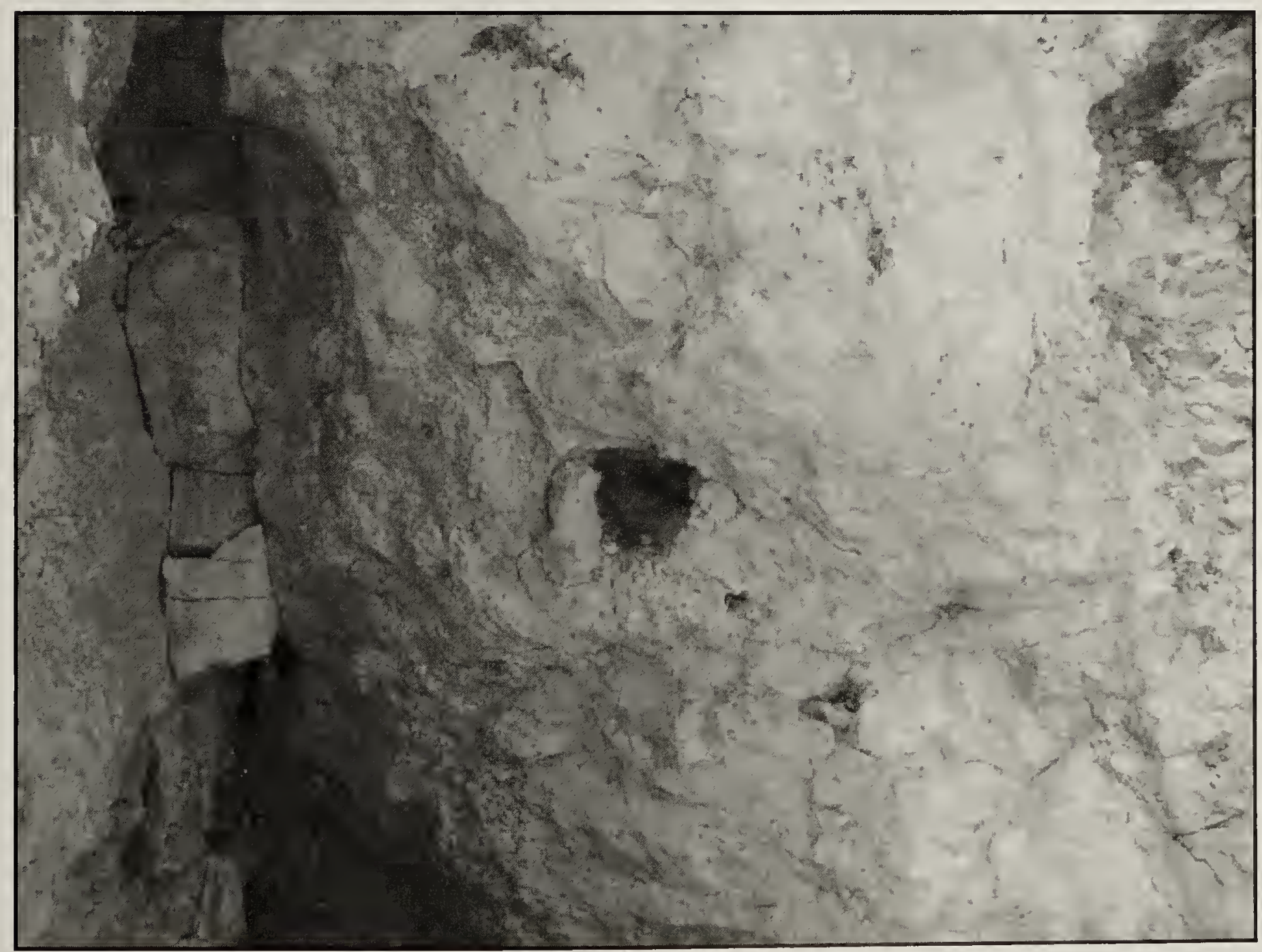

Figure 3. Nest 2, built in a small rock crevice. Note the build-up of droppings at the entrance. Photographed on June 9, 2007.

D. Raitt 


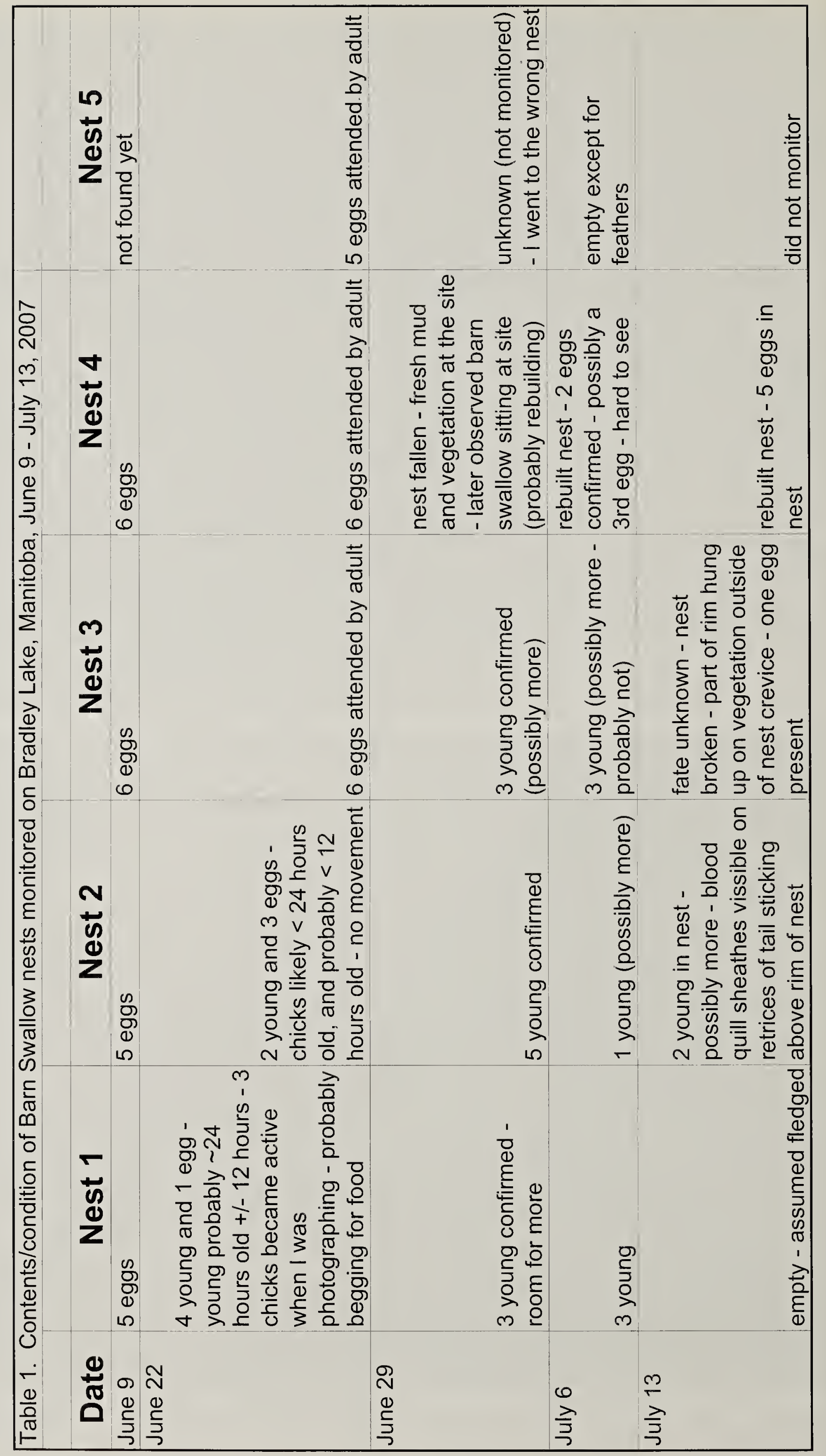


stuck on vertical rock surfaces (Figures 1 and 2) to open cups supported by rock underneath, e.g. in a small rock crevice (Figure 3 ). In all cases the nests were protected from above by rock overhangs. The season the nests were built or used was unknown, so these 18 nests may represent several years of use.

On May 7, 2007, the year's first Barn Swallows in The Pas area were reported to me by Darryl Langlois of The Pas. On May 17, I saw (from the mainland) Barn Swallows flying around the island on Bradley Lake where the nests were previously noted. Between June 9 and July 13, I visited the Bradley Lake site five times by boat to record activity. During this period, I made observations on five active nests (Table 1). Active nests were chosen for monitoring if they could be approached without damaging them or other nests, and if the contents could be viewed (from the boat) either directly or with the aid of a mirror. In many cases, due to the close proximity of rock overhangs, a mirror was held over the nest, and digital photographs were shot up toward the mirror. The digital photos were later reviewed to confirm the nest contents. Due to other commitments, I was unable to continue monitoring nests after July 13, 2007.

At two locations, I noted active Barn Swallow nests within $60 \mathrm{~cm}$ of another active Barn Swallow nest.

On July 6,2007 , I noted that, including the 5 nests I was monitoring, there were 12 active nests, and probably 4 or 5 more. Based on the number of swallows in the area and the difficulty in locating all nests, I think there may have been as many as 24 nests.

The discrepancy between my high estimate of 24 nests and the 18 located on March 24, 2007 is due in part to the fact that in March I neglected to search the north face of the island. I had incorrectly assumed that it would not be used because of its exposure to the prevailing winds. Approximately 200 meters southwest of the nesting island there is another island with similar rock faces. The island is approximately 4 to 5 times larger than the nesting island. In 2007, I saw no evidence of use there by Barn Swallows.

Speich et al. noted that possible reasons for the lack of information on natural nesting sites for Barn Swallows might be their occurrence "in remote and generally inaccessible areas where they are unlikely to be discovered," and "observers may be unaware of the significance of natural nestings and, therefore, fail to report such observations." ${ }^{4}$ In the case of Bradley Lake, the nesting site is seen by many people every year. The lake is a fairly popular fishing location (stocked with smallmouth bass), easily accessible, with a boat launch.

\section{Acknowledgements}

I wish to thank University College of the North for providing a boat, motor, and trailer for use in accessing the nesting island.

1. BETTS, N. D. W. 1916. A recent instance of the nesting of Barn Swallows on cliffs. Wilson Bulletin 28: 72-73.

2. BROWN, C. R. and M. B. BROWN. 1999. Barn Swallow (Hirundo rustica), The Birds of North America Online (A. Poole, Ed.). Ithaca: Cornell Lab of Ornithology; Retrieved from the Birds of North America Online: http://bna.birds.cornell.edu/ bna/species/452

3. KNAPTON, R.W. 1988. Unusual Bank and Barn Swallow Nesting on Lake Winnipegosis, Manitoba. Blue Jay $46: 37$

4. SPEICH, S. M., H. L. JONES, and E. M. BENEDICT. 1986. Review of the Natural Nesting of the Barn Swallow in North America. The American Midland Naturalist 115: 248-254 